cytokine. Recent studies have shown that RANKL induces HMGB1 release and it is required for RANKL-induced osteoclastogenesis in vitro and in vivo.

Objectives: To investigate the relationship of serum HMGB1 levels with RANKL/ Osteoprotegerin (OPG) axis and clinical and radiographic parameters in patients with AS.

Methods: In this cross-sectional study, serum samples for total HMGB1, sRANKL and OPG were detected from 54 tumour necrosis factor (TNF) inhibitor naive patients with AS according to the modified New York criteria [mean age 34.9 years (S.D. 7.1); duration of symptoms 8.6 years (S.D. 4.2); male gender 38 patients (70.4\%)] and 26 healthy controls. ESR, CRP, Bath AS Disease Activity Index (BASDAI), Bath AS Functional Index (BASFI) were assessed for each patient. Bone mineral density was measured using dual-energy $\mathrm{X}$-ray absorptiometry (DXA) at lumbar spine (L2-L4) and proximal femur. Lumbar spine radiographs were scored using the modified Stoke AS Spine Score (mSASSS).

Results: Serum HMGB1 levels were relatively higher in patients with AS than HCs however no statistically significant in each other. Serum HMGB1 levels correlated with CRP ( $\mathrm{rho}=0.368$ and $P=0.006$ ), ASDAS-CRP ( $\mathrm{rho}=0.358$ and $p=0.008$ ) and BASDAI ( $r h o=0.334$ and $p=0.014$ ) and BASFI ( $r h o=0.355$ and $p=0.008$ ) in patients with AS. CRP and ASDAS-CRP showed more correlated to HMGB1 serum levels than BASDAI. There was no significant correlation between HMGB1 levels with sRANKL, OPG, mSASSS and spine or femur BMD values. In addition, serum OPG levels and the ratio of SRANKL to OPG from AS patients were significantly higher than those of $\mathrm{HCs}$.

Table 1

\begin{tabular}{lccc}
\hline & AS patients $(\mathrm{n}=54)$ & Healthy controls $(\mathrm{n}=26)$ & $p$ \\
\hline Age $(\mathrm{yrs})$ & $34.9 \pm 7.1$ & $33.3 \pm 4.0$ & $\mathrm{~N} / \mathrm{A}$ \\
Body mass index $\left(\mathrm{kg} / \mathrm{m}^{2}\right)$ & $26.3 \pm 4.7$ & $26.3 \pm 2.8$ & $\mathrm{~N} / \mathrm{A}$ \\
Disease duration $(\mathrm{yrs})$ & $8.6 \pm 4.2$ & - & $\mathrm{N} / \mathrm{A}$ \\
ESR $(\mathrm{mm} / \mathrm{hr})$ & $22.0 \pm 8.5$ & - & $\mathrm{N} / \mathrm{A}$ \\
CRP $(\mathrm{mg} / \mathrm{L})$ & $11.5 \pm 8.9$ & - & $\mathrm{N} / \mathrm{A}$ \\
HMGB $(\mathrm{ng} / \mathrm{ml})$ & $337.1 \pm 166.1$ & $286.3 \pm 126.1$ & $\mathrm{~N} / \mathrm{A}$ \\
SRANKL $(\mathrm{ng} / \mathrm{ml})$ & $148.6 \pm 31.4$ & $137.2 \pm 46.9$ & $\mathrm{~N} / \mathrm{A}$ \\
OPG $(\mathrm{ng} / \mathrm{ml})$ & $285.5 \pm 68.9$ & $317.8 \pm 51.8$ & 0.02 \\
sRANKL/OPG & $0.6 \pm 0.2$ & $0.4 \pm 0.1$ & $<0.001$ \\
\hline
\end{tabular}

Conclusions: This study showed that levels of HMGB1 in the sera of AS patients, are increased compared to healty controls. Serum HMGB1 levels are related to BASDAI, ASDAS-CRP, BASFI and CRP in patients with AS. Different results in the literature on serum HMGB1 levels as well as our results support the hypothesis that HMGB1 plays a role in the pathogenesis of AS. According to our knowledge, it is the first trial evaluating association between serum HMGB1 levels with sRANKL-OPG axis, bone mineral density and new bone formation in AS patients and it seems not to be related for these conditions.

[1] Zhou Z, Han JY, Xi CX, et al. J Bone Miner Res. HMGB1 regulates RANKL-induced osteoclastogenesis in a manner dependent on RAGE.2008 Jul:23(7):1084-96.

[2] Bidwell JP, Yang J, Robling AG. Is HMGB1 an osteocyte alarmin? J Cell Biochem. 2008 Apr 15;103(6);1671-80.

Acknowledgements: Grant Support: by Erciyes University Council of Scientific Investigations (Project code: TTU-2014-5575).

Disclosure of Interest: None declared

DOI: 10.1136/annrheumdis-2017-eular.4303

\section{FRI0458 ASSESSMENT OF BONE MINERAL DENSITY IN PATIENTS WITH EARLY AXIAL SPONDYLOARTHRITIS FROM CORSAR COHORT: 2 YEARS FOLLOW UP}

O. Rumyantseva, T. Dubinina, A. Demina, D. Rumiantceva, S. Erdes, E. Agafonova, S. Krasnenko, E. Gubar. Nasonova Research Institute of Rheumatology, Moscow, Russian Federation

Background: Bone loss in patients (pts) with early axial spondyloarthritis (axSpA) is insufficiently studied and may be associated with disease activity.

Objectives: To assess the bone mineral density (BMD) in pts with early axSpA base on data from 2 years follow up of CORSAR cohort.

Methods: The research included 65 pts with axSpA (criteria ASAS 2009) with disease duration $<5$ years and age at onset $<45$ years. Pts at least 2 years follow up, $32(49,2 \%)$ male, pts mean age was $28,5(5,8)$ y., average disease duration $24,1(15,4) \mathrm{mo}, 60(92,3 \%)$ pts were HLA-B27 positive. At baseline all pts were NSAID-naïve, DMARD-naïve, anti-TNF-naïve. For 2 years all pts taking NSAIDs at therapeutic doses, part of the pts received sulfasalazine and anti-TNF. BMD was measured using dual energy $x$-ray absorptiometry (DXA) of the femoral neck (FN) and lumbar spine (LS) (L2-4) at baseline and after 1 year, and 2 years follow up. BMD reduction was defined as $Z$ score $\leq-2$ (at least one site).

Results: Low BMD at baseline founded in $9(13,8 \%)$ pts, in $10(15,3 \%)$ pts after 1 year and in $5(7,7 \%)$ pts after 2 years follow up. There were no significantly

Table 1. BMD at baseline and after 1 and 2 years follow up

\begin{tabular}{lcccc}
\hline & Baseline & 1 years after baseline & 2 years after baseline & $\mathrm{p}$ \\
\hline BMD LS mean (s.d) & $-0,759(1,13)$ & $-0,679(1,11)$ & $-0,627(1,11)$ & 0,541 \\
BMD FN mean (s.d) & $-0,527(0,91)$ & $-0,633(0,95)$ & $-0,477(1,00)$ & 0,792 \\
\hline
\end{tabular}

differences between the mean values of BMD at baseline and after 2 year, data are shown in the Table.

Conclusions: Low BMD was quite rare (14\%) in patients with early axSpA. Small frequency of BMD reduction in the Russian cohort of axSpA patients after 2 years of study is probably due to disease activity decrease on anti-inflammatory therapy. Disclosure of Interest: None declared

DOI: 10.1136/annrheumdis-2017-eular.3209

\section{FRI0459 DEVELOPMENT AND VALIDATION OF A SPANISH TOOL FOR SEMI-AUTOMATIC QUANTIFICATION OF SACROILIAC INFLAMMATION BY MAGNETIC RESONANCE IN SPONDYLOARTHRITIS (SCAISS)}

P. Zarco ${ }^{1}$, R. Almodóvar ${ }^{1}$, A. Bueno ${ }^{2}$, L.M. Molinero ${ }^{3} .{ }^{1}$ Unit Rheumatology; ${ }^{2}$ Unit Radiology, Hospital Universitario Fundación Alcorcon; ${ }^{3}$ Ingeniera ALCE, Madrid, Spain

Background: Different systems to quantify inflammatory changes in sacroiliac MRI have been developed.[1, 2] These systems include the Spondyloarthritis Research Consortium of Canada (SPARCC), the Berlin, the Aarhus-Puhakka, and Aarhus-Madsen, the Leeds, the MR Imaging of Seronegative SpA (MISS), Leeds, Sieper/Rudwaleit and Hermann/Bollow scoring systems. In addition, the use of these quantification methods is restricted to clinical trials, since their use in clinical practice is limited due to their complexity, need for trained personal, and prolonged procedural time. The development of computers and data processing software has led to significant advances in methods for image analysis. With the objective to improve interobserver quantification of sacroilitis while maintaining a practical perspective, our group has developed a semi-automated method to measure bone marrow edema (BME) in MRI images from sacroiliac (SI) joints.

Objectives: The aim of this study is to analyze the validity and reliability of the method.

Methods: The development of the method to quantify inflammation in SI joints involved software selection from a list of potential programs, process-mapping based on discussion, and tuning. Once developed, feasibility (time spent) interobserver reliability (intraclass correlation coefficient), and construct validity (convergent validity) were analysed. Two rheumatologists and a radiologist independently quantified sacroilitis from SI images from 12 patients with a diagnosis of axial SpA by the new method, and by non-automated methods to rate sacroilitis (SPARCC* and Berlin). Convergent validity, reliability and feasibility were calculated. $\left({ }^{*}\right.$ In the present study, for simplicity reasons and in order to make it closer to the developed technique, the authors modified the SPARCC method by using a single coronal section instead of the standard six consecutive ones).

Results: The interobserver reliability was high, with intraclass correlation coefficients for global score of $0.81(95 \% \mathrm{Cl}$ : $0.59-0.94)$. Convergent validity was good, with high correlation with the Berlin (rho between 0.797 and 0.913 ) and the SPARCC methods (rho between 0.566 and 0.897 ). Mean time employed in the reading procedure was 30 seconds.

Conclusions: The developed semi-automatic technique permits a fast and valid calculation of overall BME lesion at the SI joint on MRI images.

References:

[1] van der Heijde DM, Landewe RB, Hermann KG, et al. Application of the OMERACT filter to scoring methods for magnetic resonance imaging of the sacroiliac joints and the spine. Recommendations for a research agenda at OMERACT 7. J Rheumatol 2005; 32(10):2042-2047.

[2] Ostergaard M, Poggenborg RP, Axelsen MB, et al. Magnetic resonance imaging in spondyloarthritis-how to quantify findings and measure response. Best Pract Res Clin Rheumatol 2010; 24(5):637-657.

Disclosure of Interest: None declared

DOI: 10.1136/annrheumdis-2017-eular.1281

\section{FRI0460 EXTRA-ARTICULAR MANIFESTATIONS IN PATIENTS WITH AXIAL SPONDYLOARTHRITIS: A CROSS SECTIONAL STUDY FROM SOUTHERN DENMARK}

R.A. Andreasen ${ }^{1,2}$, R. Christensen ${ }^{1}$, L.E. Kristensen ${ }^{1}$, T. Ellingsen ${ }^{3,4}$, H.C. Horn ${ }^{3}$, I.M.J. Hansen $2,5 .{ }^{1}$ Rheumatology, The Parker Institute, Bispebjerg and Frederiksberg Hospital, Copenhagen; ${ }^{2}$ Rheumatology, OUH, Svendborg Hospital, Svendborg; ${ }^{3}$ Rheumatology; ${ }^{4}$ Patient data Explorative Network (OPEN), Odense University Hospital; ${ }^{5}$ Department of Clinical Research, University of Southern Denmark, Odense, Denmark

Background: Axial (ax) spondyloarthritis $(\mathrm{SpA})$ is a heterogenous group of chronic rheumatic diseases. Ax-SpA is subdivided into two groups referred to as nonradiographic and radiographic (i.e. AS) respectively. Next to the spinal and articular symptoms, many patients with SpA also have extra-articular manifestations (EAM) which contribute to reduced quality of life ${ }^{1}$. SpA appears to be more frequent in men than woman in its axial presentations, and in reference to the prototype of the disorder, AS, three male cases are documented for every female case. However, since the introduction of the new ASAS criteria for ax-SpA these differences are no longer so apparent ${ }^{2}$. Nevertheless, little is known of the differential clinical expression of SpA between males and females.

Objectives: The objective of this study was to compare patients with AS and 